\title{
Root activity, root death, and the stability of soil organic matter
}

\author{
KATE LAJTHA $1 *$ \\ DEREK PIERSON 2 \\ RICH BOWDEN 3 \\ KNUTE NADELHOFFER 4 \\ MYRNA SIMPSON 5
}

1 Dept. Crop and Soil Sciences, Oregon State University, Corvallis OR 97331; kate.lajtha@oregonstate.edu

22 Dept. Crop and Soil Sciences, Oregon State University, Corvallis OR 97331; derek.pierson@oregonstate.edu

3 Dept. Environmental Science \& Sustainability, Allegheny College, Meadville, PA 16335; rbowden@allegheny.edu

4 Dept. of Ecology \& Evolutionary Biology, Univ.

Michigan, Ann Arbor, MI 48109; knute@umich.edu

5 Department of Physical \& Environmental Sciences,

University of Toronto Scarborough, Toronto, ON,

Canada, M1C 1A4; myrna.simpson@utoronto.ca

Despite the critical roles played by soil organic matter (SOM) within the global C cycle, controls on SOM balances in ecosystems remain poorly understood. Temperature, soil mineralogy, and land management all play a role in the balance between SOM stabilization and destabilization, but the degree to which plant litter quality and quantity affect soil $\mathrm{C}$ sequestration is less well known. The international Detrital Inputs and Removal Treatment (DIRT) network was established to assess how rates and sources of plant litter inputs control the long-term stability, accumulation, and chemical nature of SOM in forested ecosystems over decadal time scales. A DIRT site was established in 1997 in a Pacific Northwest conifer forest where treatments include litter doubling, aboveground litter removal, woody debris additions, root exclusion, and the exclusion of all litter inputs. Litter doubling did not increase soil carbon stocks or surface $\mathrm{C}$ concentrations, although woody debris inputs increased particulate organic $\mathrm{C}$ contents. Removal of new root inputs also resulted in minimal changes to soil $\mathrm{C}$ concentrations, although mineral-associated organic matter (MAOM) increased significantly with root exclusion. We suggest that while living roots and inputs of high quality litter provide an important energy source to microbes that accelerates decomposition of SOM (priming), removal of live roots reduces priming while a flush of dead roots allows for increased microbial growth and the stabilization of microbial products as MAOM. 